\title{
THE BOUNDS OF ADULT LANGUAGE ACQUISITION
}

\section{Blocking and Learned Attention}

\author{
Nick C. Ellis \\ University of Michigan
}

\author{
Nuria Sagarra \\ Pennsylvania State University
}

\begin{abstract}
The current study investigates the limited attainment of adult language acquisition in terms of an associative learning phenomenon whereby earlier learned cues attentionally block those that are experienced later. Short- and long-term blocking are demonstrated in experimental investigations of learned attention in the acquisition of temporal reference in a small set of Latin phrases. In Experiment 1, previous experience with adverbial cues blocks the acquisition of verbal tense morphology, and, in contrast, early experience with tense blocks later learning of adverbs. Experiment 2 demonstrates long-term transfer effects: Native speakers of Chinese languages, which do not exhibit verb tense morphology, fail to acquire inflectional cues when adverbial and verbal cues are equally available.
\end{abstract}

Adult language acquisition typically falls far short of nativelike competence. Various explanations have been proposed for this limited attainment, such as critical periods for language acquisition, sociocultural

This research was supported by National Science Foundation Grant BCS-0717557. We thank Nina Wickens, Emily Cahill, and Katherine Martin for help in designing, piloting, scoring, and administering these experiments and Patrick Rebuschat and four anonymous SSLA reviewers for constructive comments on a prior version of this manuscript.

Address correspondence to: Nick C. Ellis, University of Michigan, 500 E. Washington Street, Ann Arbor, MI 48104; e-mail: ncellis@umich.edu. 
differences, motivational differences, and restricted input. The current study considers an alternative additional explanation: It explores adults' difficulty in acquiring foreign or second languages (L2s) in terms of cognitive principles of transfer in the associative learning of form-meaning relations in linguistic constructions. This research demonstrates learned attention in L2 learning of morphological (i.e., verbal inflections) and lexical cues (i.e., adverbs) to temporal reference.

Languages allow the same idea to be expressed in a variety of ways. For example, time is a concept fundamental to human cognition and action. All languages have rich means to express the position of events in a time line; they variously utilize tense morphology (e.g., walked vs. walk), lexical adverbs (e.g., now, next, yesterday, tomorrow), prepositional phrases (e.g., in the morning, in the future), serialization (e.g., I left work, I walked to the bus stop, I waited $10 \mathrm{~min}$ ), and calendric reference (e.g., May 12, Monday). Any stretch of discourse typically uses a selection of these cues in combination (e.g., yesterday I walked to the university but next Tuesday I'll ride the bus) (Evans, 2003). Children acquiring their first language (L1) eventually learn all of these constructions for expressing time. This is usually not the case for adults learning a L2 naturalistically (Bardovi-Harlig, 2000; Noyau, Klein, \& Dietrich, 1995; Perdue, 1993; Schumann, 1987; VanPatten, 1996).

Usage-based SLA is limited in its end state (R. Ellis, 1994; Schmidt, 1984); naturalistic or communicatively based SLA often stabilizes at a basic variety of interlanguage that falls far short of nativelike ability. This basic variety-although sufficient for everyday communicative purposespredominantly comprises only nouns, verbs, and adverbs; closed-class items-in particular, grammatical morphemes and prepositions-are rare if present at all (Bardovi-Harlig, 1992; Clahsen \& Felser, 2006; Klein, 1986; Mangubhai, 1991; VanPatten, 1996, 2006). As Klein (1998) put it, in the basic variety, "there is no functional inflection whatsoever: no tense, no aspect, no mood, no agreement, no casemarking, no gender assignment" (pp. 544-545). L2 temporal reference is initially made mostly by the use of devices such as temporal adverbials, prepositional phrases, serialization, and calendric reference; the grammatical expression of tense and aspect emerges only slowly thereafter-if at all (Bardovi-Harlig, 1992, 2000; Lee, 2002; Meisel, 1987; Noyau et al., 1995; Sagarra, 2001). SLA requires attention to meaning and form (Long, 1991), but learning form-meaning connections requires mental effort. Because the cognitive resources needed to respond to these demands are limited (Just \& Carpenter, 1992) and learning another language in adulthood consumes additional resources (Hasegawa, Carpenter, \& Just, 2002), learners have to select which aspects of the input to process (Gass, Svetics, \& Lemelin, 2003; MacWhinney, 1987; Sagarra, 2007; Schmidt, 1993).

One factor that determines selection is cue salience: Prepositional phrases, temporal adverbs, and other lexical cues to time are quite 
pronounced in the speech stream, whereas verbal inflections are not (as in yesterday I walked). Zipf's (1949) principle of least effort describes how frequent words become shorter with use. Speakers want to minimize articulatory effort and hence encourage brevity and phonological reduction. As more frequent words are used again and again, automatization of production causes shortening. The most frequent items of language are the closed-class words and grammatical morphemes; it is thus these items that are the least salient in the speech stream. Additionally, because shorter words tend to be more homophonous, they are also more ambiguous in their interpretations (N. C. Ellis, 2008a). This low salience and low reliability tends to make grammatical cues less learnable (N. C. Ellis, 2006d; Goldschneider \& DeKeyser, 2001) and could underlie late learners' difficulty in processing and producing L2 verbal morphology (Jiang, 2004; Sato \& Felser, 2008; Zobl \& Liceras, 1994).

However, salience and reliability affect both L1 and L2 acquisition. There must be something else that accounts for the bounds of SLA. Established explanations of the limited end state emphasize either external or internal causes (Doughty \& Long, 2003; Kroll \& De Groot, 2005). External-cause theories center on limited exposure to L2 comprehensible input (Krashen, 1994), insufficient opportunities for L2 output (Swain, 2005), or social interactional factors (e.g., adults are less immersed in the L2, their language development is less scaffolded by their interlocutors; Schumann, 1978). Internal-cause theories include critical periods, after which adults seem to be less capable of language learning (DeKeyser \& Larson-Hall, 2005), performance deficits (Hopp, 2007; Lardiere, 2007; White, 2003), lack of access to Universal Grammar (Hawkins \& Franceschina, 2004), or preference for shallow over deep processing, whereby lexical and semantic cues are used as opposed to syntactic ones (Clahsen \& Felser, 2006). The current study describes experiments that explore a competing line of explanation: that of learning history as it affects attention to language.

\section{BACKGROUND}

Associative learning theory documents a range of effects of transfer and inhibition that shift learners' attention to input as a result of prior experience. Kamin (1969) and Kruschke (2006) described the phenomenon of blocking (N. C. Ellis, 2007). Associating a particular stimulus A with a particular outcome X makes it more difficult to learn that cue B (subsequently paired with the same outcome) is also a good predictor. Thus, for example, if a pigeon learns that a conditioned stimulus (e.g., a light) is a reliable predictor of an unconditioned stimulus (e.g., the onset of some painful stimulus such as a shock), then it will not become conditioned to or learn that any other conditioned stimulus predicts the unconditioned 
stimulus (e.g., that a bell predicts the onset of the shock in the same way the light did). Once the animal learns one reliable association with the conditioned stimulus, this essentially blocks further associations. Blocking is an effect of learned attention (Kamin; Kruschke \& Blair, 2000; Mackintosh, 1975). It is a highly robust and widespread phenomenon that occurs across animal and human learning (Rescorla \& Wagner, 1972; Shanks, 1995; Wills, 2005).

There are many situations in natural language in which cues are redundant (Schmidt, 2001; Terrell, 1991; VanPatten, 1996) and thus-as a consequence of blocking - might be less readily learned. If L1 experience has led a learner to look elsewhere for cues to interpretation, he or she might use these cues where available in the L2; the principles of associative learning predict that this reliance on $\mathrm{L} 1$ cues will be to the detriment of learning other cues that might also be relevant. For example, L1-derived knowledge that there are reliable lexical cues to temporal reference (words like yesterday, gestern, hier, ayer) might block the acquisition of verb tense morphology from analysis of utterances such as yesterday I walked or hier nous sommes allés au cinéma "yesterday we went to the movies." It is not just tense that might be subject to such effects. Naturalistic —-but not instructed-L2 learners tend to omit plural $-s$ endings on nouns that are preceded by quantifiers (Pica, 1983). During sentence processing, late Chinese learners of English tend to focus on the plurality of the subject rather than the ending of the verb (Jiang, 2004). These effects might result from the frequent overshadowing of inflections for number by the more obvious plurality of the clear subject of the verb (seven cats run- $\varnothing$ down the road, the black cat- $\varnothing$ runs down the road). Given that it is not uncommon in natural language for grammatical cues to be foreshadowed by more salient lexical and discourse cues, SLA thus seems to be a problem space that might be particularly susceptible to learned attention effects such as blocking and overshadowing.

The importance of attention in modulating SLA has long been acknowledged, as summarized in Schmidt's (2001) review of the literature:

The concept of attention is necessary in order to understand virtually every aspect of second language acquisition (L2 acquisition), including the development of interlanguages over time, variation within IL [interlanguage] at particular points in time, the development of L2 fluency, the role of individual differences such as motivation, aptitude, and learning strategies in L2 learning, and the ways in which interaction, negotiation for meaning, and all forms of instruction contribute to language learning. (p. 3)

With regard to linguistic features as cues, Schmidt went on to conclude that "since many features of L2 input are likely to be infrequent, non-salient, and communicatively redundant, intentionally focused 
attention may be a practical (though not theoretical) necessity for successful language learning" (p. 3). Associative learning theory makes focused attention a theoretical necessity as well.

Indeed, various theories of SLA incorporate related notions of transfer and learned attention. The competition model (MacWhinney, 2001; MacWhinney \& Bates, 1989; MacWhinney, Bates, \& Kliegl, 1984) was explicitly formulated to deal with competition between multiple linguistic cues to interpretation. Input processing theory (VanPatten, 1996) includes the lexical preference principle whereby "learners will process lexical items for meaning before grammatical forms when both encode the same semantic information" (VanPatten, 2006, p. 118). This principle encapsulates the mounting evidence that L2 learners prefer lexical to grammatical cues (for evidence from oral tasks, see Lee, Cadierno, Glass, and VanPatten, 1997; Musumeci, 1989; for written tasks, see Lee, 1999; Rossomondo, 2007; Sagarra, 2001, 2007; Sagarra and Ellis, 2010). The preference for nonredundancy principle also plays a role in input processing: "Learners are more likely to process nonredundant meaningful grammatical markers before they process redundant meaningful markers" (VanPatten, 2006, p. 119). The associative-cognitive CREED (i.e., that SLA is construction-based, rational, exemplar-driven, emergent, and dialectic; N. C. Ellis, 2006a, 2006c, 2006d, 2008b) describes the limited end state typical of SLA directly in terms of learned attention, salience, overshadowing, and blocking.

The current study explores these phenomena of learned attention in two language learning experiments. The first experiment demonstrates short-term instructional sequence effects in adults learning temporal reference in Latin translations through the standard blocking experimental paradigm (Kruschke, 2006) combined with linguistic content. The second experiment provides evidence for long-term language transfer effects whereby the nature of the learners' L1 (i.e., whether it exhibits verb tense morphology) biases the acquisition of verbal inflectional versus lexical cues to temporal reference in a small set of Latin phrases.

\section{EXPERIMENT 1}

This experiment involves the learning of a small number of Latin expressions and their English translations. The effects of successive learning of different types of cues for temporal reference-adverbs (hodie "today," heri "yesterday," cras "tomorrow") and verbal inflections (cogito "I think," cogitavi "I thought," cogitabo "I will think")—are investigated. This experiment determines whether the acquisition of one set of cues is impaired if another is already known to be a reliable indicator of event time. 


\section{Participants}

Student volunteers from a major university in the United States were paid $\$ 10$ for their participation in the experiment. None of the participants had learned Latin previously. They were randomly assigned to one of three groups. The adverb pretraining group consisted of 19 native speakers of English (9 men and 10 women), ages 19-27 ( $M=20.9$ years). The verb pretraining group consisted of 17 native speakers of English (5 men and 12 women), ages $18-33$ ( $M=21.8$ years). The no pretraining control group consisted of 18 native speakers of English (6 men and 12 women), ages $18-25(M=20.2$ years $)$.

\section{Materials and Procedure}

The experiment was programmed in E-Prime software (Schneider, Eschman, \& Zuccolotto, 2002). It took less than $1 \mathrm{hr}$ and included four phases: pretraining (Phase 1), sentence decoding (Phase 2), reception testing (Phase 3), and production testing (Phase 4). The procedure is schematized in Figure 1.

Phase 1. Participants in the adverb pretraining group completed 36 randomized trials in which they saw either the adverb hodie "today" or the adverb heri "yesterday." It should be noted that Phase 1 involved only present and past temporal reference; no future reference was included. The participants had to choose the correct translation by clicking on either today or yesterday with the mouse. These alternatives appeared in counterbalanced positions on the screen. A correct choice returned the feedback correct, whereas an incorrect response was met with, for example, the feedback wrong - the meaning of hodie is today.

Participants in the verb pretraining group in Phase 1 were exposed to inflectional cues in the verb forms cogito "I think" and cogitavi "I thought" instead of adverbial cues and had to choose the correct translation. Otherwise, the procedure was the same as for the adverb pretraining group. It should again be noted that Phase 1 involved only present and past temporal reference; no future reference was included. The no pretraining control group did not participate in Phase 1; however, all three groups of participants underwent identical Phases 2, 3, and 4.

Phase 2. Participants were exposed to six sentences (hodie cogito "today I think," cogito hodie "I think today," heri cogitavi "yesterday I thought," cogitavi heri "I thought yesterday," cras cogitabo "tomorrow I 


\begin{tabular}{|c|c|c|c|c|}
\hline $\begin{array}{c}\text { Phase 1 } \\
\text { (pretraining) } \\
36 \text { randomized trials }\end{array}$ & $\begin{array}{c}\text { Phase } 2 \\
\text { (sentence decoding) } \\
36 \text { trials randomized } \\
\text { in blocks of } 6\end{array}$ & \multicolumn{2}{|c|}{$\begin{array}{c}\text { Phase } 3 \\
\text { (reception testing) } \\
48 \text { trials randomized in blocks } \\
\text { of } 24\end{array}$} & $\begin{array}{c}\text { Phase } 4 \\
\text { (production testing) } \\
18 \text { trials randomized } \\
\text { in blocks of } 9\end{array}$ \\
\hline $\begin{array}{l}\text { Adverb pretraining group } \\
\text { Hodie "today" } \\
\text { Heri "yesterday" }\end{array}$ & Present & $\begin{array}{l}\text { Stimulus } \\
\text { Hodie } \\
\text { Heri } \\
\text { Cras } \\
\text { Cogito } \\
\text { Cogitavi } \\
\text { Cogitabo }\end{array}$ & $\begin{array}{l}\text { midiem } \\
3 \\
1 \\
5 \\
3 \\
1 \\
5\end{array}$ & \\
\hline $\begin{array}{l}\text { Verb pretraining group } \\
\text { Cogito "I think" } \\
\text { Cogitavi "I thought" }\end{array}$ & $\begin{array}{l}\text { Hodie cogito } \\
\text { Cogito hodie } \\
\text { Past } \\
\text { Heri cogitavi } \\
\text { Cogitavi heri } \\
\text { Future }\end{array}$ & $\begin{array}{l}\text { Hodie cogito } \\
\text { Hodie cogitavi } \\
\text { Hodie cogitabo } \\
\text { Heri cogito } \\
\text { Heri cogitavi } \\
\text { Heri cogitabo } \\
\text { Cras cogito } \\
\text { Cras cogitavi } \\
\text { Cras cogitabo }\end{array}$ & $\begin{array}{l}3 \\
2 \\
4 \\
2 \\
1 \\
3 \\
4 \\
3 \\
5\end{array}$ & $\begin{array}{l}\text { I thought } \\
\text { I think } \\
\text { I will think } \\
\text { Yesterday } \\
\text { Today } \\
\text { Tomorrow } \\
\text { Yesterday I thought } \\
\text { Today I think }\end{array}$ \\
\hline $\begin{array}{l}\text { Control group } \\
\text { No pretraining }\end{array}$ & $\begin{array}{l}\text { Cras cogitabo } \\
\text { Cogitabo cras }\end{array}$ & $\begin{array}{l}\text { Cogito hodie } \\
\text { Cogitavi hodie } \\
\text { Cogitabo hodie } \\
\text { Cogito heri } \\
\text { Cogitavi heri } \\
\text { Cogitabo heri } \\
\text { Cogito cras } \\
\text { Cogitavi cras } \\
\text { Cogitabo cras }\end{array}$ & $\begin{array}{l}3 \\
2 \\
4 \\
2 \\
1 \\
3 \\
4 \\
3 \\
5\end{array}$ & Tomorrow I will think \\
\hline
\end{tabular}

Figure 1. Stimuli used in each phase of Experiment 1. The control group did not participate in the pretraining phase. The rating scale for Phase 3 ranged from 1 (past) to 5 (future). In Phase 4, participants were asked to provide the Latin equivalent of each English phrase.

will think," and cogitabo cras "I will think tomorrow"), which appropriately combined the adverb with a verb-three in adverb-verb and three in verb-adverb word order-and were asked to choose whether these sentences referred to the present, the past, or the future. Both word orders were used to counterbalance which cue was experienced first across sentences. There were six blocks of these trials to consolidate learning. Participants were given feedback if incorrect.

Phase 3. As in competition model studies of cue use (MacWhinney, 1987), in the reception test, all combinations of adverb (hodie "today," heri "yesterday," cras "tomorrow") and verb tense marking (cogito "I think," cogitavi "I thought," cogitabo "I will think") were combined, and participants were asked to judge the temporal reference of each string on a 5-point scale. The factorial crossing of these cues resulted in logical strings that the learners had seen previously (equivalent to, e.g., today I think and tomorrow I will think), words that had not been experienced 
separately (such as cras "tomorrow" and cogitabo "I will think"), and strange combinations (equivalent to, e.g., yesterday I think). On the rating scale, 1 corresponded to past, 2 corresponded to between past and present, 3 corresponded to present, 4 corresponded to between present and future, and 5 corresponded to future. Participants were asked to choose the number that they thought best applied. There was no feedback in this phase. Both word orders were tested, and the block was repeated twice to allow reliable assessment of the relative weight that learners put on interpreting adverbial and inflectional cues to temporal reference. The average weight of the two cues within each string, which will be called the semidiem (this being a Latin experiment), is provided in Figure 1.

Phase 4. In the final, production testing phase, participants were asked to translate from English to Latin by typing the Latin equivalents of the various elements to which they had been exposed: I thought, I think, I will think, yesterday, today, tomorrow, yesterday I thought, today I think, or tomorrow I will think. There was no feedback on the responses.

The dependent variables were accuracy of learner responses on the adverbs and verbs in the reception and production testing of Phases 3 and 4. The logic of the experiment is simple. Every sentence in Phase 2 contains two cues, an adverb and a morphological inflection, which both cue the same temporal reference. Every participant experiences these two cues together, and control participants never see them separately. If participants pay equal attention to these two cues, Phase 3 judgments should be equally affected by both cues, and, in Phase 4, participants should be equally good at producing adverbs and verbal inflections. If, however, more attention is paid to the adverbial (or verbal) cues, judgments will be swayed from the semidiem toward the adverbial (or verbal morphological) cues in Phase 3, and participants will better produce these forms in Phase 4.

Control group performance in Phases 3 and 4 thus indicates how native English speakers naturally weigh these two cues-whether, for example, more salient lexical cues overshadow less obvious morphological ones. Performance in the adverb pretraining group assesses potential learned attention and blocking as a detrimental effect of prior learning of lexical cues upon later learning of inflectional cues. Performance in the verb pretraining group assesses potential blocking as a detrimental effect of prior learning of inflectional cues upon later learning of lexical cues.

Responses given in Phases 3 and 4 could reflect specific previously learned associations as proactive interference effects: As in paired associate learning experiments, memory for association A-B is worse after prior learning of A-C (e.g., an association such as present-cogito "I think" 
would block present-hodie "today") in comparison with a control condition that involves prior learning of unrelated material D-E (Baddeley, 1976). However, the future reference sentences cras cogitabo "tomorrow I will think" and cogitabo cras "I will think tomorrow" are a special case in that every participant-whether in the control, verb pretraining, or adverb pretraining group-only experiences these two cues together in Phase 2. None of the participants had prior experience of these forms in Phase 1; therefore, these items are a pure indicator of learned attention to adverbial or verbal cue type.

\section{Results}

Perception Data. Despite their lack of pretraining, the control group learned the temporal reference of the whole sentences in Phase 2 in much the same way as the adverb and verb pretraining groups. In the second half of Phase 2, control group performance was 88\% correct, compared to $97 \%$ for both the adverb and verb pretraining groups. However, in Phase 3, participants in the three groups differed in their cue use. Figure 2 illustrates the average group judgment of the temporal reference of each construction in terms of deviation from the semidiem average. The expressions are ordered from extreme past on the left to extreme future on the right. For strings made up of conflicting cues, the large solid diamond shows the temporal information provided by the verb and the large solid circle represents the temporal information provided by the adverb. In the sentence cogito heri "I think yesterday," for example, with a verb reference of 3 and an adverb reference of 1 , the respective deviations from the semidiem are +1 and -1 ; for cogitabo heri "I will think yesterday," the verb reference is 5 , the adverb reference is 1 , and thus the relative deviations from the semidiem are +2 and -2 .

Figure 2 shows that the three groups react to the cues present in the strings of Phase 3 in very different ways. ${ }^{1}$ For two-word strings, which include temporal information cued by both an adverb and a verbal inflection, the verb pretraining group follows the verbal cue and the adverb pretraining group follows the adverbial cue when the two cues deviate. The judgments of these two groups thus move in opposite directions: When one group leans to the future, the other leans to the past. In these cases of cue conflict, the control group judgment lies in between, which seems to suggest that these participants attend to both cues equally.

These impressions are confirmed by three multiple regression analyses, one for each group, in which the dependent variable is the group mean temporal interpretation for each of the 18 two-word strings and the independent variables are the interpretations cued by both the 


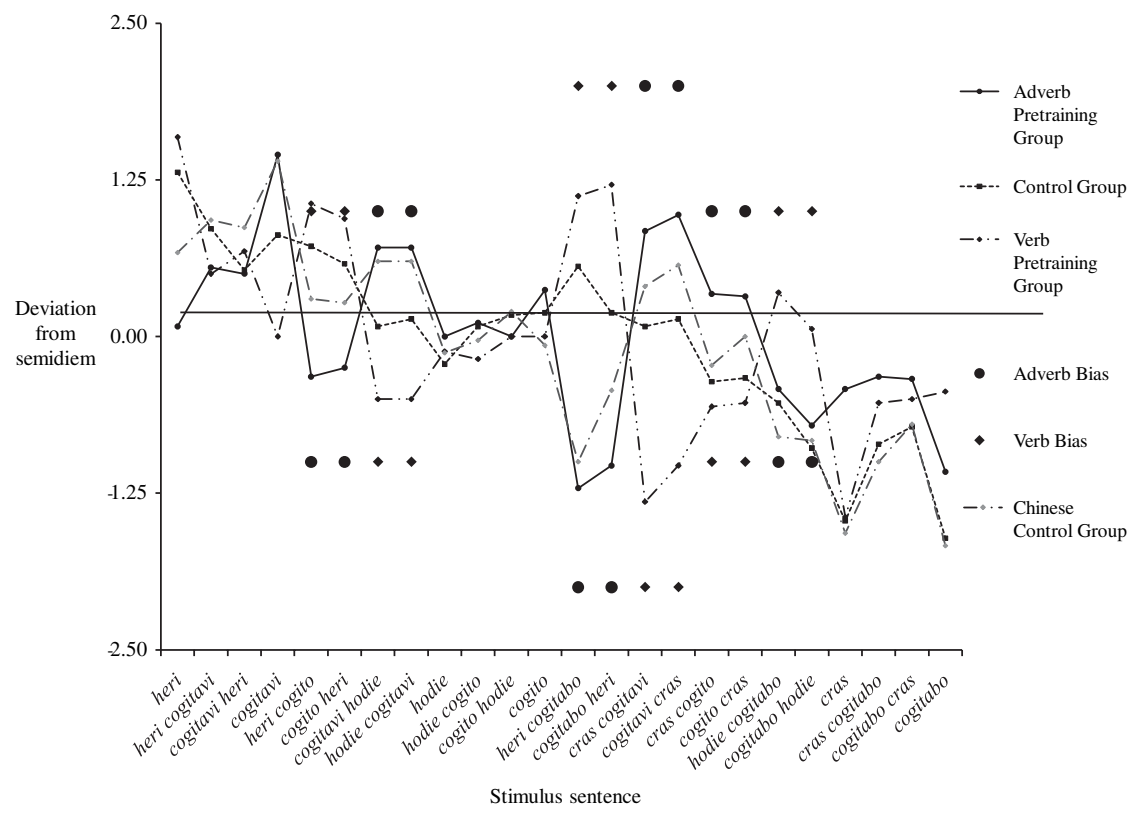

Figure 2. Mean deviations of Phase 3 temporal interpretations from semidiem average. Bias symbols mark the deviation of the adverbial cues (circles) and verb inflection cues (diamonds) when these cues conflict.

adverbial cue and the verbal inflection. The differential cue use by each of the three groups, in standardized $\beta$ coefficients, is presented in Table 1 , along with the $R^{2}$ from a separate regression of group mean temporal interpretation against construction semidiem.

The participants who first learned adverbial cues to temporal reference continued to use those cues to the exclusion of others. In subsequent utterances that contained both adverbial and inflectional cues to event time, verbal morphology accounted for only $5 \%$ of their performance, whereas adverbial cues determined $94 \%$. Similarly, the participants who first learned inflectional cues to temporal reference continued

Table 1. Differential cue use across groups in Experiment 1

\begin{tabular}{lccc}
\hline Value & Adverb pretraining & Verb pretraining & Control \\
\hline $\begin{array}{l}\text { Adjusted } R^{2} \\
\text { Time }\end{array}$ & 0.98 & 0.96 & 0.85 \\
$\begin{array}{l}\text { Semidiem } \\
\text { explained }\end{array}$ & $0.97 \mathrm{adv}+0.23 \mathrm{v}$ & $0.12 \mathrm{adv}+0.97 \mathrm{v}$ & $0.60 \mathrm{adv}+0.72 \mathrm{v}$ \\
\hline
\end{tabular}


to use those cues to the exclusion of others. In subsequent utterances that contained both adverbial and inflectional cues to event time, adverbial cues accounted for $1.4 \%$ of performance, whereas verbal morphology determined $94 \%$.

However, control group participants, who had no prior experience of Latin adverbial or morphological cues to time before exposure to sentences that contained both cues, learned to attend to both cues, with $52 \%$ of the variance in their judgments accounted for by the verbal cues and $36 \%$ by the adverbs. The control group's performance is thus much closer to the semidiem. When their ratings were used as predictors of the semidiem scores in a separate multiple regression, they explained $85 \%$ of the correct averaged interpretations, compared to just $71 \%$ for the adverb pretraining and 59\% for the verb pretraining groups, respectively.

These differences in the relative amounts of variance explained by the adverb and verb cues on the mean group ratings over the Phase 3 test strings are substantial. Nevertheless, as with all learning experiments, it is appropriate to ask whether the group performance means are truly reflective of the individuals within that group or whether they provide a central tendency that blurs individual within-group differences. To demonstrate that these patterns are reliable across individual group members, for each individual's Phase 3 responses, the degree to which temporal rating on each construction correlated with the information provided separately by both the verb and adverbial cue was calculated. These Pearson's $r$ correlations thus show the degree to which each participant is biased by each cue. Figure 3, which plots each individual in the space defined by these correlations, reveals that the large majority of verb pretraining group participants were heavily influenced by the verb cues but hardly at all by the adverbs; conversely, the large majority of the adverb pretraining group participants were strongly influenced by the adverbial cues to the exclusion of any information provided by the verb inflections. However, the control group participants were not equally affected by these two cues, contrary to what the group mean suggests: The distribution of these participants does not lie along the $45 \%$ diagonal but is rather more bimodal, with some individuals influenced more by the adverbial cues and others by the inflections. This finding is in line with previous research that demonstrated that when dealing with multiple cues to interpretation in the early stages of acquisition, learners typically focus on one cue at a time, exploring its utility and only introducing others later, one by one, as the additional cues reduce error of estimation (Cheng \& Holyoak, 1995; MacWhinney, 1987; Matessa \& Anderson, 2000; McDonald, 1986).

The group means of these correlations are shown in Figure 4. Due to different orders in the steps of calculation, these group means of the individual correlations within each group are slightly different from the 


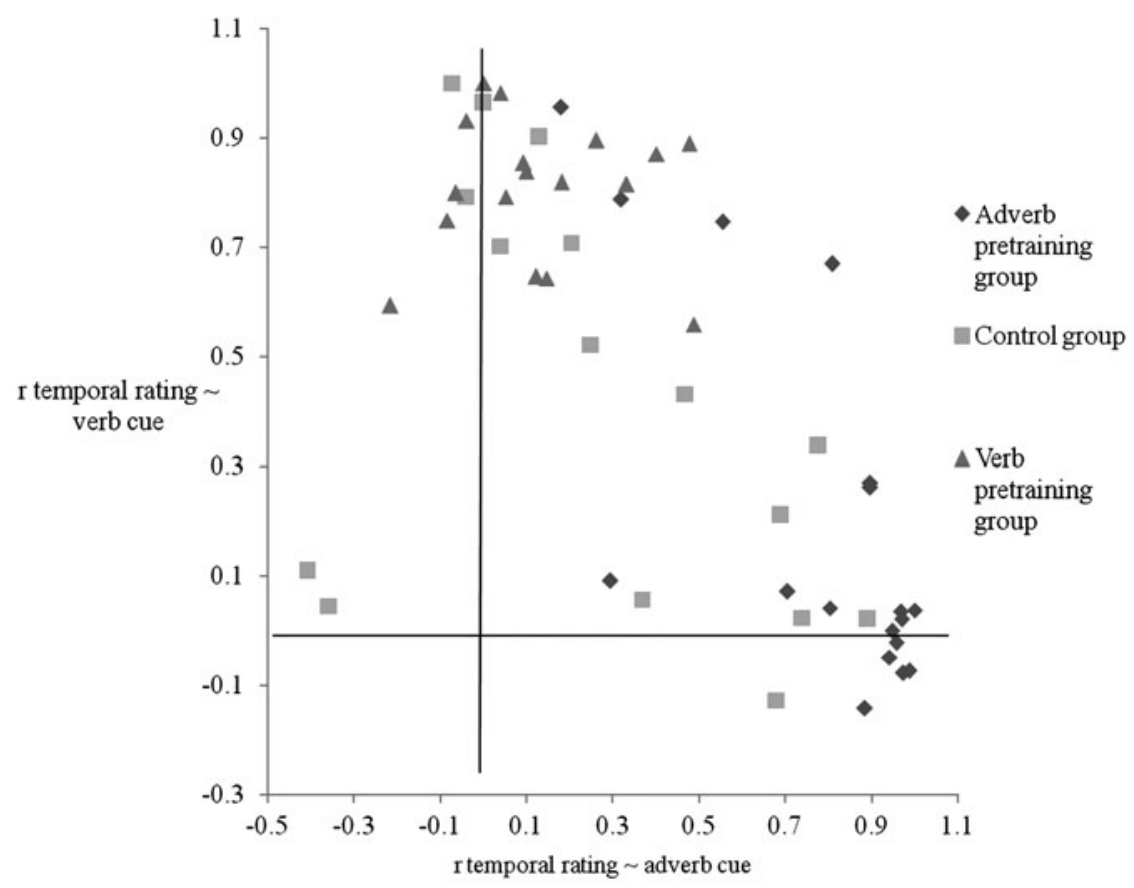

Figure 3. Sensitivity to adverbial and verbal inflectional cues to temporal reference in each participant.

correlations of the group mean scores over the individuals, but the patterns are substantially the same. The adverb pretraining group continues to be heavily influenced by the adverb but not the verb, the verb pretraining group is influenced much more by the verb than the adverb, and the control group participants are influenced by both cues. A twofactor ANOVA ( 3 groups $\times 2$ cues) reveals a highly significant interaction between group and cue use, $F(2,49)=25.41, p<.001$. Post hoc Tukey's honestly significant differences (HSD) tests indicate that the adverb pretraining group differs in adverb cue use from both the control $(p<.001)$ and the verb pretraining groups $(p<.001)$ but that these two groups do not differ significantly from one another. Similarly, in verb cue use, the verb pretraining group differs from both the control $(p<.001)$ and the adverb pretraining groups $(p<.001)$; however, these two groups do not differ significantly from one another.

Production Data. The production data parallel these patterns. Table 2 shows the representative responses of two individuals from the production testing phase of the experiment, during which participants were asked, for the first time, to produce utterances in Latin that 


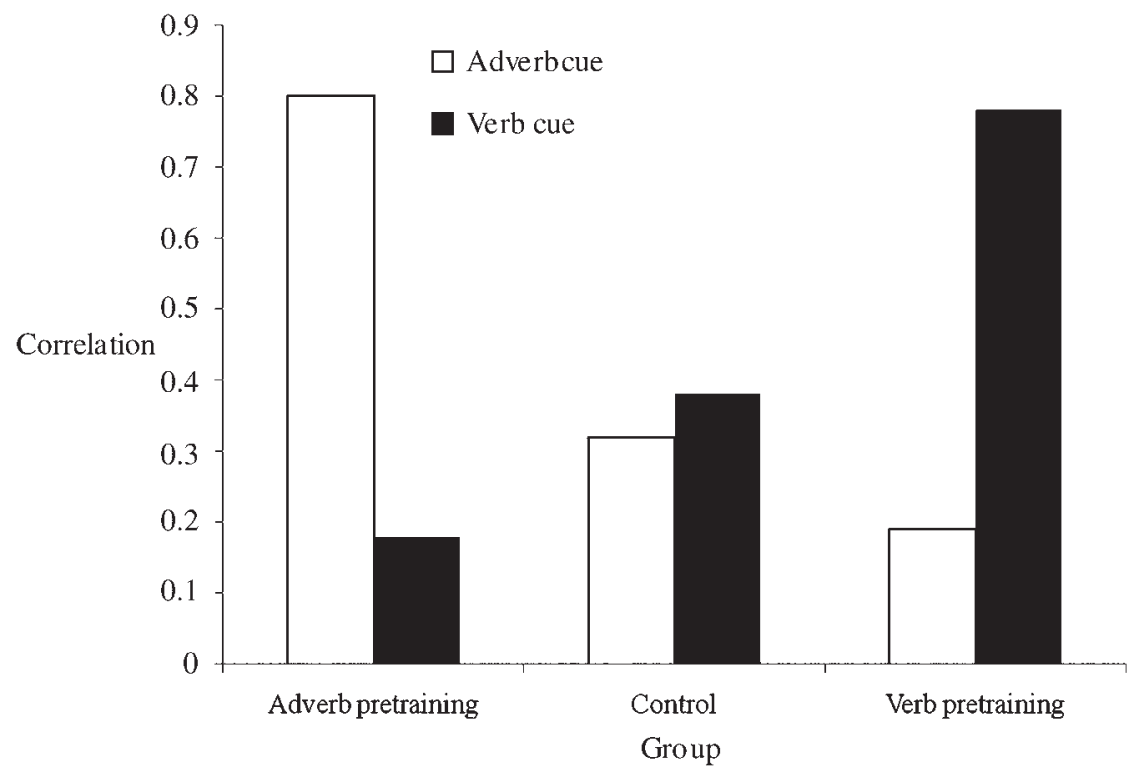

Figure 4. Group mean correlations between individual participants' Phase 3 sentence ratings and the information given by the corresponding adverb and verb cues.

related to event time. The adverb pretraining group participant provided the appropriate adverb on every trial, whether explicitly required to or not, and exhibited a central tendency to use the relatively unchanging verb form cogativo (an idiosyncratic blend of their own invention). The verb pretraining participant provided the appropriate tense inflections where required. When asked for a bare adverb, this participant provided one-although usually the wrong one, which suggests that the items in this category had begun to be acquired but not yet properly mapped to corresponding meanings. The production testing of Phase 4 was less transparent for control group participants because they had not learned the translations in Phase 1. Nevertheless, most control group participants attempted this phase and, like language learners the world over, made a reasonable stab at generalizing from what they already knew.

To analyze the production data across individuals, each response was given a score of 0 to 1 for adverb or verb: For the adverb, a score of 0 was given if the wrong adverb or no adverb was provided, and a score of 1 was given if the adverb was provided and spelled correctly. Adverbs that were misspelled by two letters but still close to the target form (e.g., codi for hodie "today") earned an intermediate score of .33 and those misspelled by only one letter received a score of .66. Similarly, for the verb, a score of 0 was given if no verb was provided, whereas the correct verb and correct spelling earned a score of 1 . Intermediate scores of .33 were 
Table 2. Representative responses from Phase 4 production testing

\begin{tabular}{llll}
\hline Stimulus & $\begin{array}{c}\text { Correct } \\
\text { response }\end{array}$ & $\begin{array}{c}\text { Adverb group } \\
\text { participant } \\
\text { response }\end{array}$ & $\begin{array}{l}\text { Verb group } \\
\text { participant } \\
\text { response }\end{array}$ \\
\hline I thought & Cogitavi & Heri cogativi & Cogitavi \\
I think & Cogito & Cogativo & Cogito \\
I will think & Cogitabo & Cogitivo cras & Cogitabo \\
Yesterday & Heri & Heri & Cras \\
Today & Hodie & Hodie & Cras \\
Tomorrow & Cras & Cras & Heri \\
Yesterday I thought & Heri cogitavi & Heri cogativo & Cras cogitavi \\
Today I think & Hodie cogito & Hodie cogativo & Cogito \\
Tomorrow I will think & Cras cogitabo & Cras cogativo & Cogitabo \\
I thought & Cogitavi & Cogativo heri & Cogitavi \\
I think & Cogito & Cogativo & Cogito \\
I will think & Cogitabo & Cogativo cras & Cogitabo \\
Yesterday & Heri & Heri & Cras \\
Today & Hodie & Hodie & Hodie \\
Tomorrow & Cras & Cras & Hodie \\
Yesterday I thought & Heri cogitavi & Heri cogativo & Cras cogitavi \\
Today I think & Hodie cogitavi & Hodie cogativi & Cogito \\
Tomorrow I will think & Cras cogitabo & Cras cogativo & Heri cogitabo \\
\hline
\end{tabular}

given for the correct verb with an incorrect but consistent ending or if the last letter of the morpheme ending was correct; a score of .66 was given for verbs with correct morphology but misspelled roots, or if the whole form (both root and morpheme) was misspelled by just one letter.

The group means of these production scores are shown in Figure 5. A two-factor ANOVA ( 3 groups $\times 2$ cues) reveals a highly significant interaction between group and cue use, $F(2,49)=31.30, p<.001$. Post hoc Tukey's HSD tests indicate that the adverb pretraining group differs from both the control $(p<.001)$ and verb pretraining groups $(p<.001)$, in correct adverb use but that these two groups do not differ significantly from one another. Similarly, the verb pretraining group differs from both the control $(p<.001)$ and adverb pretraining groups $(p<$ .001 ) in the correct use of verb morphology, but these two groups do not differ significantly from one another. The adverb pretraining group was very accurate at producing the adverb but less accurate on the verb $(p<.001)$; the verb pretraining group was better at producing the verb than the adverb $(p<.001)$; and control group production of both verbs and adverbs was roughly equivalent.

Cues or Content? A key element of the design of this experiment is that all participants had equivalent exposure to the future items cogitabo 


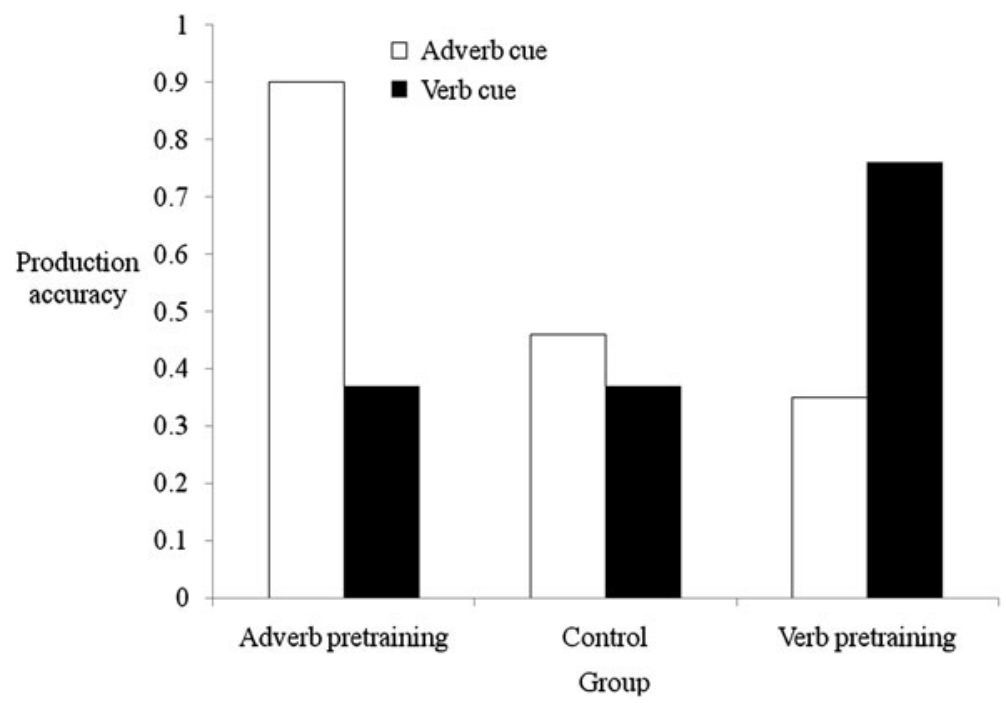

Figure 5. Group mean production scores for adverb and verb cues.

cras "I will think tomorrow" and cras cogitabo "tomorrow I will think" during Phase 2 and that none of the participants had any prior experience with these items or with any reference to future temporality. Every participant in the experiment encountered these utterances six times each in Phase 2 and were shown that these forms relate to the future. Analysis of these items therefore allows for the identification of pure effects of blocking without prior training on specific content. Performance on these items must reflect attentional biases to particular dimensions of cue (adverb vs. verbal inflection) rather than to particular words or tenses because neither these forms nor their functions had been encountered prior to Phase 2. The pattern in Figure 2 suggests that in Phase 3, the adverb and verb pretraining groups are as unalike in their performance on the future items cras "tomorrow" and cogitabo "I will think" as for the other past and present reference items.

Figure 6 isolates these future items and shows the three groups' temporality ratings for the adverb cras "tomorrow" and the verb form cogitabo "I will think" when they are experienced separately in Phase 3. Both of these items, if fully acquired, should receive a maximum future rating of 5. However, the adverb pretraining group has learned from the two-word utterances experienced during Phase 2 about cras "tomorrow," whereas the verb pretraining group has learned from the same exposure to the same utterances about cogitabo "I will think." A two-factor ANOVA ( 3 groups $\times 2$ cues) reveals a highly significant interaction between group and cue use, $F(2,49)=4.29, p<.02$. 


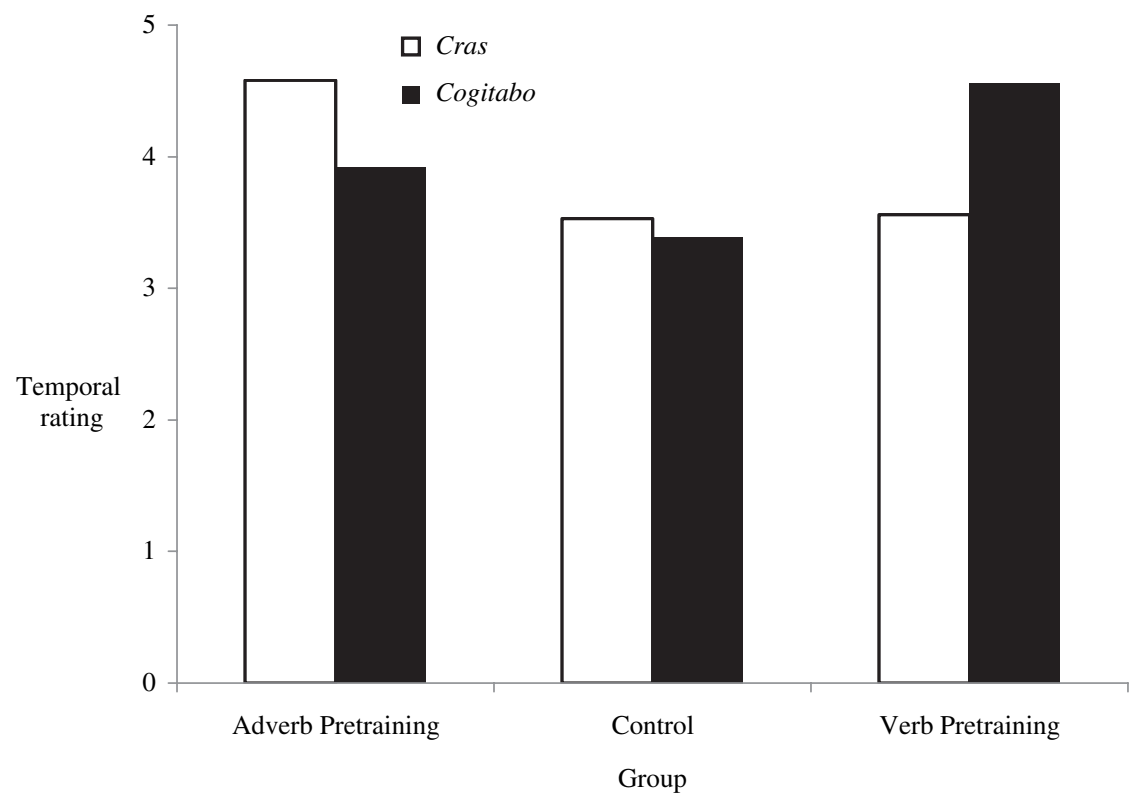

Figure 6. Mean rating scores for the adverb and verb cues cras "tomorrow" and cogitabo "I will think" when experienced as isolated stimuli; 5 indicates extreme future.

These items can also be isolated in production. During Phase 4, the participants were asked for the Latin translations of, on separate trials, tomorrow, I will think, and tomorrow I will think. Figure 7 shows the accuracy of the three groups on the adverb and the verb when tapped individually (Figure $7 \mathrm{a}$ ) and when elicited together in the one utterance tomorrow I will think (Figure 7b).

A two-factor ANOVA (3 groups $\times 2$ cues) reveals a significant Group $\times$ Cue interaction in the data of Figure $7 \mathrm{a}, F(2,49)=10.04, p<.001$. Post hoc Tukey's HSD tests demonstrate that the adverb pretraining group performed significantly better than the verb pretraining group on cras "tomorrow" ( $p<.01$; one tailed) and that the verb pretraining group performed significantly better than the adverb pretraining group on cogitabo "I will think" ( $p<.05$; one tailed).

A two-factor ANOVA ( 3 groups $\times 2$ cues) shows there to be a highly significant Group $\times$ Cue interaction in the data of Figure $7 \mathrm{~b}, F(2,49)=$ $17.97, p<.000005$. Post hoc Tukey's HSD tests demonstrate that the adverb pretraining group performed significantly better than the verb pretraining group on cras "tomorrow" ( $p<.0001$; one tailed) and that the verb pretraining group performed significantly better than the adverb pretraining group on cogitabo "I will think" ( $p<.01$; one tailed). 

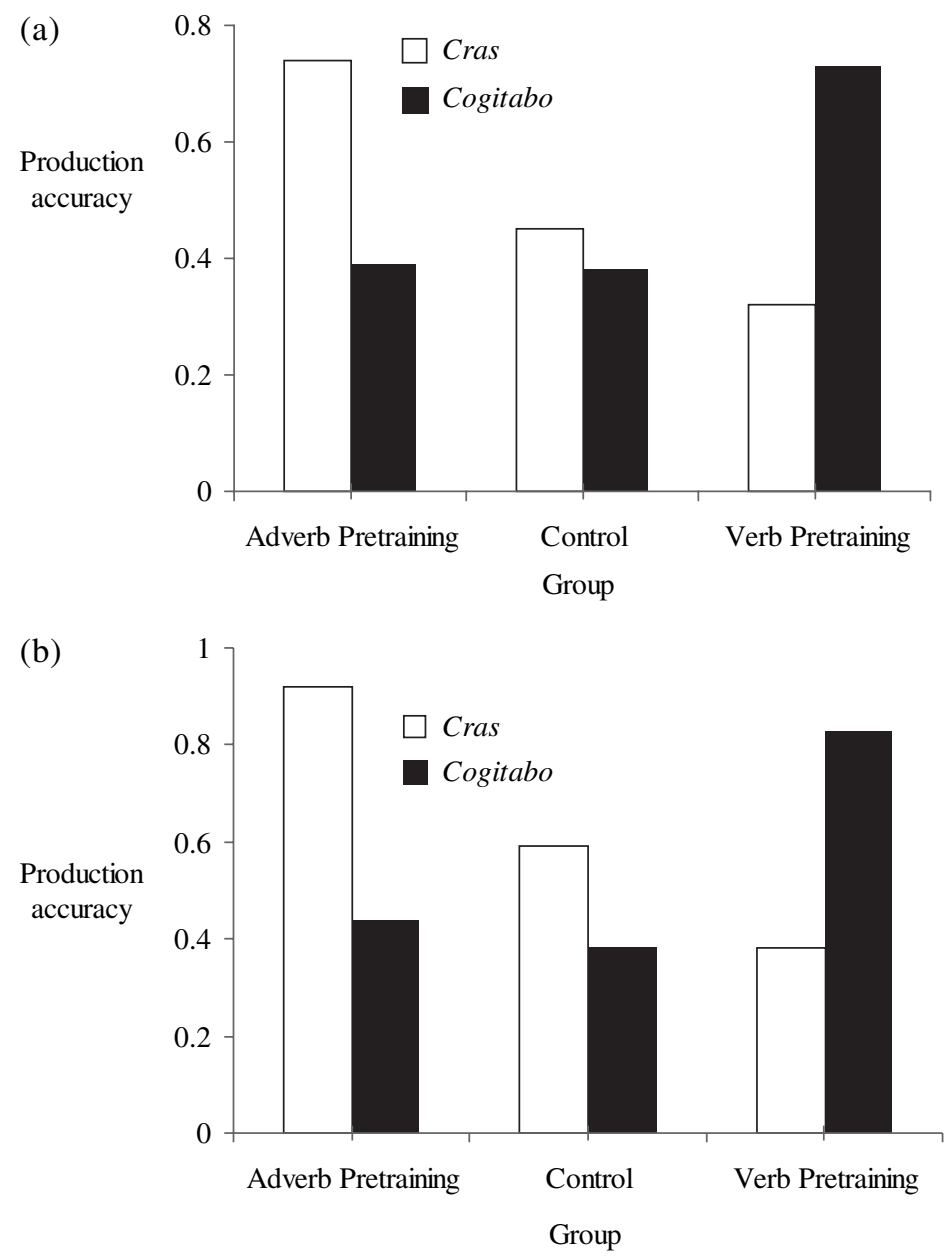

Figure 7. Mean production scores for the adverb and verb cues cras and cogitabo when prompted by (a) isolated stimuli today or I will think or (b) composite stimuli tomorrow I will think.

\section{Discussion}

These quantitative results illustrate large and significant effects of blocking in the early acquisition of language. Early learning of either two temporal adverbs or two verb tense inflections causes learners to concentrate on different cues in understanding subsequently experienced sentences. This usage, in turn, leads learners to attend to different cue dimensions as important communicators of temporal information. Differential cue use across participant groups in referring 
to the future is particularly noteworthy. Every participant experienced the same Latin future utterances (cras cogitabo "tomorrow I will think" and cogitabo cras "I will think tomorrow") the same number of times in Phase 2. Frequency of usage and exposure was the same across groups; nevertheless, experience and what was learned was quite different. Therefore, as in the case of associative learning of other cue-outcome interpretations in medical diagnoses or in stock market predictions (Kruschke \& Blair, 2000; Shanks, 1995), these data demonstrate that for linguistic constructions as well, prior learning of one type of cue blocks the later acquisition of other cue dimensions-even those that are reliable predictors in their own right. These learned attention effects have been demonstrated here in the short term through an experiment that manipulated instructional sequence. Experiment 2 examines whether blocking also occurs in the longer term.

\section{EXPERIMENT 2}

Usage-based views of language acquisition maintain that short-term effects lead to long-term effects (Barlow \& Kemmer, 2000; Collins \& Ellis, 2009 ; N. C. Ellis, 1998, 2003; Ellis \& Cadierno, 2009) as the individual increments of learning integrate over time to form the processes, representations, and attentional biases that constitute human minds. How the L1 maps onto experience influences expectations and learning of a L2; there are large effects of crosslinguistic transfer on SLA (MacWhinney, 1997; Odlin, 1989; Robinson \& Ellis, 2008). By these experiencebased accounts, limited adult language attainment is grounded in L1 experience, entrenchment, and transfer rather than in age or biology (N. C. Ellis, 2006d).

Experiment 2 investigated whether long-term learned attention effects that stem from L1 experience also bias cue acquisition in this experimental paradigm. In Chinese language varieties, there is no morphology, free or bound, that corresponds to tense. Instead, Chinese speakers make heavy use of temporal adverbials, both adverbs and prepositional phrases, to encode temporal meanings. ${ }^{2}$ It would be expected, therefore, that L1 experience would lead to long-term biases toward these types of cues, with consequent blocking of verbal inflectional cues.

\section{Participants}

Fifteen L1 Chinese students from a major U. S. university participated in this experiment. All students were bilingual, with an advanced language proficiency that was deemed sufficient upon application to the university 
to allow study through the medium of English. They were volunteers and were paid $\$ 10$ for their participation.

\section{Procedure}

The participants took part in an exact replication of the no pretraining control procedure of Experiment 1. It consisted of sentence decoding (Phase 2), reception testing (Phase 3), and production testing (Phase 4).

\section{Results}

Perception Data. The Phase 3 performance of the L1 Chinese participants in terms of deviation from semidiem judgment is shown in Figure 2. It can be seen that the means tend toward the adverb bias, which indicates that these participants are tracking the information given by the adverbial cue much more than that of the verbal morphology. This tendency is confirmed by the results of the multiple regression analyses for the whole group. Compared to the results from Experiment 1, the L1 Chinese group results more closely resemble those of the original adverb pretraining group rather than the original control group, as shown in Table 3.

As in Experiment 1, each L1 Chinese participant's temporal rating responses from Phase 3 were correlated with the information provided separately by both the verb cue and the adverbial cue to show the degree to which each participant was biased by each of these cues. These data are compared to those of the L1 English control participants of Experiment 1 in Figure 8a. An ANOVA revealed a significant interaction between group and cue use, $F(1,29)=4.23, p<.05$. A $t$ test showed that the L1 Chinese participants were significantly less sensitive than the L1 English participants to verb cues, $t(29)=1.88, p<.05$ (one tailed), and that the Chinese L1 participants were more affected by the adverb cues than the verb morphology, $t(14)=2.05, p<.05$ (one tailed).

Table 3. Differential cue use across groups

\begin{tabular}{lccc}
\hline Value & L1 Chinese control & L1 English control & Adverb pretraining \\
\hline Adjusted $R^{2}$ & 0.91 & 0.85 & 0.98 \\
Time & $0.91 \mathrm{adv}+0.29 \mathrm{v}$ & $0.60 \mathrm{adv}+0.72 \mathrm{v}$ & $0.97 \mathrm{adv}+0.23 \mathrm{v}$ \\
$\begin{array}{l}\text { Semidiem } \\
\text { explained }\end{array}$ & $71 \%$ & $85 \%$ & $71 \%$ \\
\hline
\end{tabular}




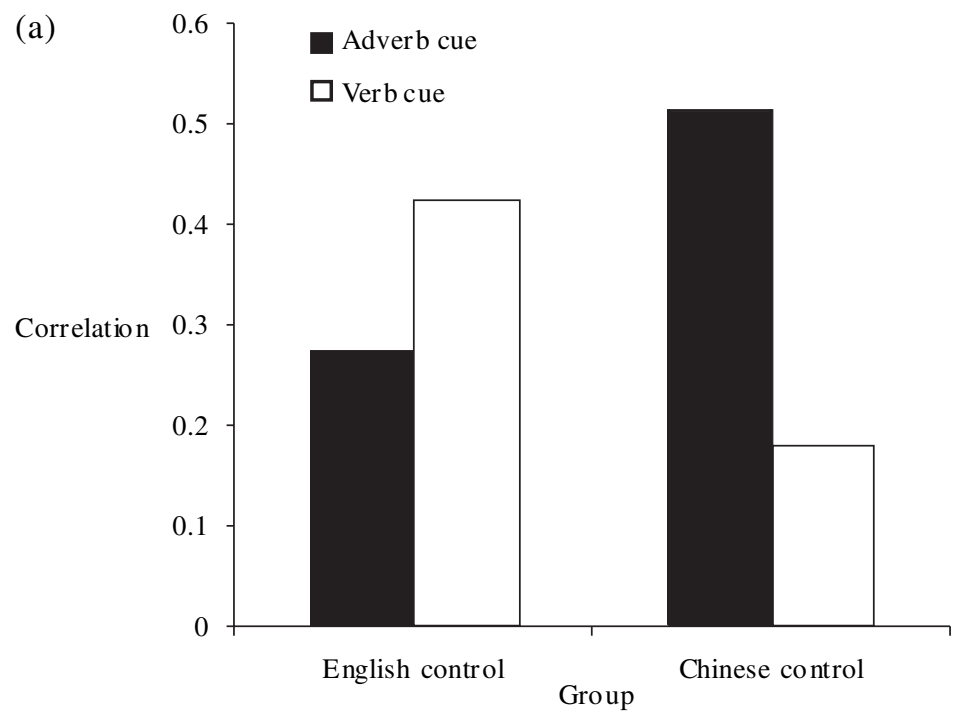

(b)

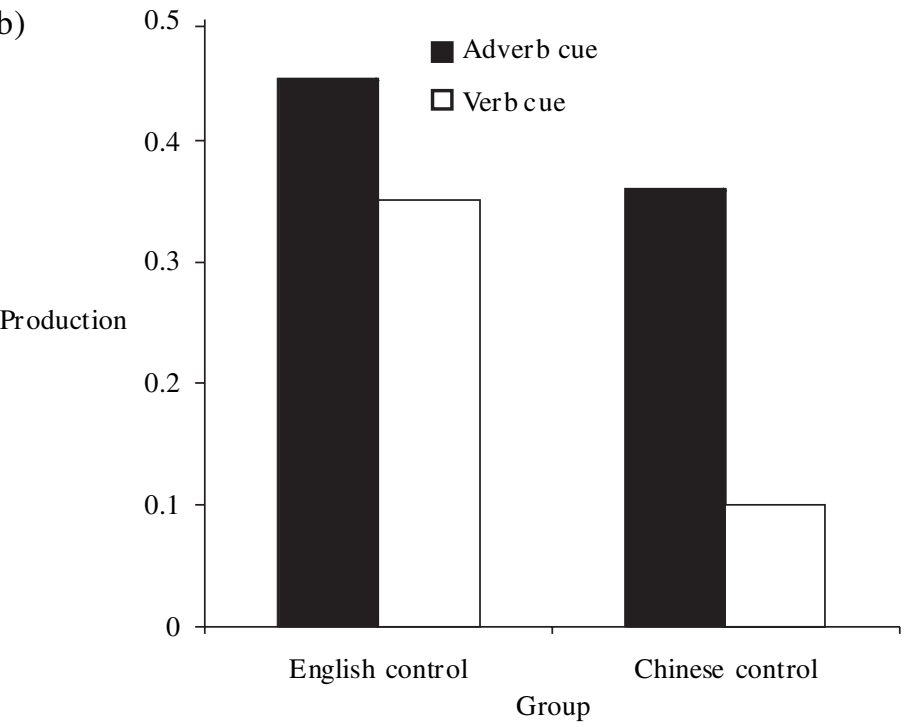

Figure 8. Group means of (a) Pearson's $r$ correlations between individual participants' ratings of Phase 3 utterances and the information given by the corresponding adverb and verb cues and (b) accuracy in Phase 4 adverb and verb production.

Production Data. The L1 Chinese participants' production of adverbs and verbs in Phase 4 was scored as in Experiment 1, and these scores are compared to those of the L1 English control participants of that experiment in Figure 8b. Although an ANOVA reveals no significant 
interaction, $F(1,29)=1.58, p=.21$, a $t$ test nevertheless demonstrated that the L1 Chinese participants were significantly less able to produce verb cues than the L1 English participants, $t(31)=3.66, p<.001$, and that the L1 Chinese participants were better able to produce the adverb cues than the verb morphology, $t(14)=2.87, p<.01$ (one tailed).

\section{Discussion}

These findings confirm that a lifetime of prior L1 usage results in longterm influence of attention to language, processing bias, and subsequent blocking of cue learning. The results of Experiment 2 are compelling in that the participants had been exposed to a L2-namely, the English in which they had become quite proficient-prior to the Latin learning experiment; this SLA experience must have brought these learners' attention to the potential productivity of inflectional cues in tense marking.

\section{CONCLUSIONS}

These experiments demonstrate clear effects of both short- and longterm attentional bias and consequent blocking of cue acquisition: Early learned language cues block the acquisition of later ones. By these same means, it seems that L2 learners' use of adverbs and other devices for expressing temporality blocks their acquisition of less salient and less reliable verb morphology, thus resulting in the so-called basic variety of a limited L2 end state. If this is indeed the case, two questions immediately come to mind: First, why do children acquiring their L1 seem not to experience this blocking? Second, why do the adults in the control group of Experiment 1 not favor the adverbial over the morphological cues? Each of these questions will be addressed in turn.

First, studies that compare L1 and L2 acquisition of different grammatical features indicate that children focus on morphosyntactic cues rather than lexical-semantic cues, unlike adult learners (Clahsen \& Felser, 2006; Felser \& Clahsen, 2009; Granfeldt, 2005; Lew-Williams \& Fernald, 2007). Why should knowledge of lexical and pragmatic means for communicating temporal reference block the acquisition of temporal morphology in SLA but not in L1 acquisition? This could be because young children do not yet have the relevant lexical and pragmatic knowledge. As children acquire their L1, they are also learning about the world and about various discourse strategies at the same time. Young children do not yet know about the convention of recounting events in their order of occurrence, nor do they clearly understand the 
meaning of temporal adverbs. Studies that have directly compared the acquisition of different systems of marking temporality report that morphological means of temporal reference precede the use of temporal adverbials in children's speech (Dale \& Fenson, 1996; Nelson, 1991, 1996; Pawlak, Oehlrich, \& Weist, 2006): Comprehension studies suggest that 3-year-olds are able to distinguish minimal tense-aspect morphological contrasts but not contrasts between lexical forms such as when and then or before and after (Weist, Atanassova, Wysocka, \& Pawlak, 1999 ) and that 2-year-olds can differentiate past and present tenses on the basis of the auxiliaries will and did, copula be, and progressive forms but are not aided by the inclusion of temporal adverbials (Valian, 2006). Adults, however, as a result of their L1 experience, know these things; they know there are reliable and salient means of expressing past time (e.g., yesterday) that are far simpler than the nonsalient and ambiguous morphological means that vary in complex ways by person and number, and so on. These already known cues might therefore block the acquisition of temporal morphology. In a sentence such as yesterday I walked, the morphological tense marker is redundant; successful interpretation of the message does not require processing of this marking, and lack of processing entails lack of acquisition. These child comprehension studies suggest that in L1 acquisition (in contrast to SLA), the acquisition of different cues to temporality does not favor adverbials over morphology. Nevertheless, there remains important research to be done, which would involve the collection and analysis of dense longitudinal corpora of naturalistic acquisition of English (and other languages) as a L1 and a L2 to compare the relative proportional use of different temporal markers in the L1 and L2, and to investigate children's use of these forms in production rather than comprehension.

Second, why is there no strong bias toward the acquisition of adverbs in the no pretraining control participants of Experiment 1? It seems that the matched attention to verbal and adverbial cues among the control participants-however clearly this cue use differentiates these participants from those pretrained with verbal or adverbial cues-is not wholly reflective of natural language learning. The stimuli in the present experiments represented a meager subset of Latin phrases, a sort of mini-language in which the three adverbs differ from one another in relatively slight ways (hodie "today," heri "yesterday," cras "tomorrow") that approximated the similarity of the verbal inflections (cogito "I think," cogitavi "I thought," cogitabo "I will think"). In natural languages, this is not the typical case. Verbal morphology, due to its high frequency, is typically of low salience in its surface manifestations compared to lexical cues (yesterday, today, tomorrow vs. I walked, I walk-Ø, I'll walk) and, thus, inflections are typically overshadowed by more salient lexical and discourse cues (Bates \& Goodman, 1997; N. C. Ellis, 2006b, 2006d). In Ellis and Sagarra (2010), the experimental paradigm is extended such that the morphological cues come in a more naturally complete state in 
which the inflections reflect tense and person (cogito, cogitas, cogitat, "I think, you think, he thinks;" cogitavi, cogitavisti, cogitavit, "I thought, you thought, he thought;" cogitabo, cogitabis, cogitabit, "I will think, you will think, he will think") in a design otherwise parallel to that of the current study. Under these conditions, participants come to rely much more on the adverbial cues, with performance in the control no pretraining group summarized in a multiple regression as Time $=0.93$ Adverb +0.17 Verb $($ compared with Time $=0.60$ Adverb +0.72 Verb in Experiment 1). Thus, it seems that adult learners are biased toward reliable, salient lexical cues to temporality and that this bias can block acquisition of less salient, complex morphological cues.

It should be acknowledged that this experiment represents language learning in its simplest, most basic form. In the control group, participants were exposed to two-word utterances and learned in less than 1 hr how these refer in some way to the past, the present, or the future. Nevertheless, the study has been designed in this way to allow for tight replicable comparisons. The current study has shown that language learning is sensitive to L1 background and to effects of varying sequences of cue exposure. The experimental paradigm is currently being extended to include eye-movement investigation of attention, assessment of implicit and explicit processing, and focus-on-form instruction, among other theoretical issues. Therefore, the current study is meant to serve as a simple but interesting language learning paradigm.

These demonstrations of learned attention and blocking in SLA do not deny the importance of frequency effects in tuning the implicit language system (N. C. Ellis, 2002a, 2006c). As argued in N. C. Ellis (2002b), before any cue can be implicitly tallied, it must first be consolidated as a representation that can enter into subsequent processing. Conscious noticing of the cue can allow this initial registration (N. C. Ellis, 2005). Cues of low physical salience or low reliability of cue-interpretation mapping can go unnoticed even after thousands of encounters (N. C. Ellis, 2006d), as can cues that, as a result of prior experience and blocking, have low psychological salience:

\footnotetext{
What we attend to is determined by our prior experience. Salience is as much a psychological as a physical property; many affordances are cultural, goal-driven, and emergent. What is important is what is important to us-it is not the things of the world that concern us, it is our thoughts of those things. Long-term attentional biases relevant to the learning of constructions emerge from experience. . . . On the whole, the learning, representation, and processing of language is part of the same dynamic network system. (N. C. Ellis, 2005, pp. 340-341)
}

Many questions have yet to be answered. Can these effects be shown in the classroom learning of a more complete sample of language in which a wide range of cues are combined and compete for attention? In our 
ongoing parallel research, we address this question through eye-tracking and sentence-processing paradigms, to investigate learning and attention to lexical and morphological L2 cues in the more ecologically valid environment of several semesters of university undergraduate Spanish language courses. Do these effects also apply in naturalistic SLA? To what extent are these attentional biases overt or covert? These experiments could be extended using eye movements (Kruschke, Kappenman, \& Hetrick, 2005) and other measures of unconscious knowledge (Dienes, 2004, 2008; Dienes \& Scott, 2005). Given that proficient language learners use cues in combination and that multiple cues in interaction provide highly constrained solutions that cannot be attained from individual cues alone, how do other cues become integrated into the learner's inference (MacWhinney, 1987)? What role does the relative salience of these cues play in the way they are used? Are learners with higher working memory capacity better able to process redundant verbal morphology that expresses temporal reference (Sagarra, 2007; Sagarra \& Ellis, 2010)? Can focus-on-form instruction, which makes learners aware of these cues, facilitate acquisition (N. C. Ellis, 2005)? Can processing instruction, which makes the use of these cues necessary, optimize acquisition (VanPatten, 1996)?

In conclusion, the findings of these experiments reinforce the possibility that understanding the limited attainment of adult L2 learning does not require reference to critical periods or to language acquisition devices but rather follows from the cognitive science of the associative learning of linguistic constructions. Simon (1957) spent much of his career as one of the founders of cognitive science exploring the bounds of human rationality. He showed how limited working memory and attentional biases entail that, at times, we must satisfice rather than optimize in our intelligence and problem solving. Adult L2 acquirers are limited in working memory and time on task and also have attentional biases to language. Temporal adverbs are known to be more reliable than the nonsalient and ambiguous verbal inflections, and learners can usually satisfice and get their message across by lexical means alone-however ungrammatical, the basic variety is communicatively effective. Adult language learning and the rest of human cognition share the same bounds.

(Received 16 October 2009)

\section{NOTES}

1. Figure 2 also includes a line that represents a L1 Chinese group from Experiment 2, which can be ignored for now.

2. Chinese language varieties have aspectual markers that differ in use based on features such as focus and modality. This fact, coupled with the absence of verbal inflectional morphology, characterizes these varieties as exclusively aspect languages (Lin, 2006; Xiao \& McEnery, 2004). 


\section{REFERENCES}

Baddeley, A. D. (1976). The psychology of memory. New York: Harper and Row.

Bardovi-Harlig, K. (1992). The use of adverbials and natural order in the development of temporal expression. International Review of Applied Linguistics in Language Teaching, 30, 299-320.

Bardovi-Harlig, K. (2000). Tense and aspect in second language acquisition: Form, meaning, and use. Oxford: Blackwell.

Barlow, M., \& Kemmer, S. (Eds.). (2000). Usage based models of language. Stanford, CA: Center for the Study of Language and Information Publications.

Bates, E., \& Goodman, J. C. (1997). On the inseparability of grammar and the lexicon: Evidence from acquisition, aphasia and real-time processing. Language and Cognitive Processes, 12, 507-586.

Cheng, P. W., \& Holyoak, K. J. (1995). Adaptive systems as intuitive statisticians: Causality, contingency, and prediction. In J.-A. Meyer \& H. Roitblat (Eds.), Comparative approaches to cognition (pp. 271-302). Cambridge, MA: MIT Press.

Clahsen, H., \& Felser, C. (2006). Grammatical processing in language learners. Applied Psycholinguistics, 27, 3-42.

Collins, L., \& Ellis, N. C. (Eds.). (2009). Input and second language construction learning: Frequency, form, and function [Special issue]. Modern Language Journal, 93(3).

Dale, P. S., \& Fenson, L. (1996). Lexical development norms for young children. Behavioral Research Methods, Instruments, and Computers, 28, 125-127.

DeKeyser, R., \& Larson-Hall, J. (2005). What does the critical period really mean? In J. F. Kroll \& A. M. B. De Groot (Eds.), Handbook of bilingualism: Psycholinguistic approaches (pp. 88-108). Oxford: Oxford University Press.

Dienes, Z. (2004). Assumptions of subjective measures of unconscious mental states: Higher order thoughts and bias. Journal of Consciousness Studies, 11, 25-45.

Dienes, Z. (2008). Subjective measures of unconscious knowledge. Progress in Brain Research, 168, 49-64.

Dienes, Z., \& Scott, R. (2005). Measuring unconscious knowledge: Distinguishing structural knowledge and judgment knowledge. Psychological Research, 69, 338-351.

Doughty, C. J., \& Long, M. H. (Eds.). (2003). The handbook of second language acquisition. Oxford: Blackwell.

Ellis, N. C. (1998). Emergentism, connectionism and language learning. Language Learning, $48,631-664$.

Ellis, N. C. (2002a). Frequency effects in language processing: A review with implications for theories of implicit and explicit language acquisition. Studies in Second Language Acquisition, 24, 143-188.

Ellis, N. C. (2002b). Reflections on frequency effects in language processing. Studies in Second Language Acquisition, 24, 297-339.

Ellis, N. C. (2003). Constructions, chunking, and connectionism: The emergence of second language structure. In C. J. Doughty \& M. H. Long (Eds.), The handbook of second language acquisition (pp. 33-68). Oxford: Blackwell.

Ellis, N. C. (2005). At the interface: Dynamic interactions of explicit and implicit language knowledge. Studies in Second Language Acquisition, 27, 305-352.

Ellis, N. C. (2006a). The associative-cognitive CREED. In B. VanPatten \& J. Williams (Eds.), Theories in second language acquisition: An introduction (pp. 77-96). Mahwah, NJ: Erlbaum.

Ellis, N. C. (2006b). Cognitive perspectives on SLA: The associative cognitive CREED. AILA Review, 19, 100-121.

Ellis, N. C. (2006c). Language acquisition as rational contingency learning. Applied Linguistics, $27,1-24$.

Ellis, N. C. (2006d). Selective attention and transfer phenomena in SLA: Contingency, cue competition, salience, interference, overshadowing, blocking, and perceptual learning. Applied Linguistics, 27, 1-31.

Ellis, N. C. (2007). Blocking and learned attention in language acquisition. In D. S. McNamara \& J. G. Trafton (Eds.), Proceedings of the 29th annual Cognitive Science Society (pp. 965-970). Austin, TX: Cognitive Science Society.

Ellis, N. C. (2008a). The dynamics of language use, language change, and first and second language acquisition. Modern Language Journal, 41, 232-249. 
Ellis, N. C. (2008b). Usage-based and form-focused language acquisition: The associative learning of constructions, learned-attention, and the limited L2 endstate. In P. Robinson \& N. C. Ellis (Eds.), Handbook of cognitive linguistics and second language acquisition (pp. 372-405). London: Routledge.

Ellis, N. C., \& Cadierno, T. (2009). Constructing a second language [Special section]. Annual Review of Cognitive Linguistics, 7, 111-290.

Ellis, N. C., \& Sagarra, N. (2010). Learned attention and blocking in the acquisition of second language tense. Unpublished manuscript.

Ellis, R. (1994). The study of second language acquisition. Oxford: Oxford University Press.

Evans, V. (2003). The structure of time: Language, meaning and temporal cognition. Amsterdam: Benjamins.

Felser, C., \& Clahsen, H. (2009). Grammatical processing of spoken language in child and adult language learners. Journal of Psycholinguistic Research, 38, 305-319.

Gass, S. M., Svetics, I., \& Lemelin, S. (2003). Differential effects of attention. Language Learning, 53, 495-543.

Goldschneider, J. M., \& DeKeyser, R. (2001). Explaining the "natural order of L2 morpheme acquisition" in English: A meta-analysis of multiple determinants. Language Learning, $51,1-50$.

Granfeldt, J. (2005). The development of gender attribution and gender concord in French: A comparison of bilingual first and second language learners. In J. Dewaele (Ed.), Focus on French as a foreign language: Multidisciplinary approaches (pp. 164-190). Clevedon, UK: Multilingual Matters.

Hasegawa, M., Carpenter, P. A., \& Just, M. A. (2002). An fMRI study of bilingual sentence comprehension and workload. Neuroimage, 15, 647-660.

Hawkins, R., \& Franceschina, F. (2004). Explaining the acquisition and non-acquisition of determiner-noun gender concord in French and Spanish. In P. Prévost \& J. Paradis (Eds.), The acquisition of French in different contexts (pp. 175-206). Amsterdam: Benjamins.

Hopp, H. (2007). Ultimate attainment at the interfaces in second language acquisition: Grammar and processing. Groningen, The Netherlands: Grodil Press.

Jiang, N. (2004). Morphological insensitivity in second language processing. Applied Psycholinguistics, 25, 603-634.

Just, M. A., \& Carpenter, P. A. (1992). A capacity theory of working memory: Individual differences in comprehension. Psychological Review, 99, 122-149.

Kamin, L. J. (1969). Predictability, surprise, attention, and conditioning. In B. A. Campbell \& R. M. Church (Eds.), Punishment and aversive behavior (pp. 276-296). New York: Appleton-Century-Crofts.

Klein, W. (1986). Second language acquisition. New York: Cambridge University Press.

Klein, W. (1998). The contribution of second language acquisition research. Language Learning, 48, 527-550.

Krashen, S. D. (1994). The input hypothesis and its rivals. In N. C. Ellis (Ed.), Implicit and explicit language learning (pp. 45-78). San Diego, CA: Academic Press.

Kroll, J. F., \& De Groot, A. M. B. (Eds.). (2005). Handbook of bilingualism: Psycholinguistic approaches. Oxford: Oxford University Press.

Kruschke, J. K. (2006, June). Learned attention. Paper presented at the Fifth International Conference on Development and Learning, Bloomington, IN.

Kruschke, J. K., \& Blair, N. J. (2000). Blocking and backward blocking involve learned inattention. Psychonomic Bulletin and Review, 7, 636-645.

Kruschke, J. K., Kappenman, E. S., \& Hetrick, W. P. (2005). Eye gaze and individual differences consistent with learned attention in associative blocking and highlighting. Journal of Experimental Psychology: Learning, Memory, and Cognition, 31, 830-845.

Lardiere, D. (2007). Feature assembly in second language acquisition. In J. Liceras, H. Zobl, \& H. Goodluck (Eds.), The role of formal features in second language acquisition (pp. 106-140). Mahwah, NJ: Erlbaum.

Lee, J. F. (1999). On levels of processing and levels of comprehension. In J. Gutiérrez-Rexach \& F. Martínez-Gil (Eds.), Advances in Hispanic linguistics (pp. 42-59). Somerville, MA: Cascadilla Press.

Lee, J. F. (2002). The incidental acquisition of Spanish future morphology through reading in a second language. Studies in Second Language Acquisition, 24, 55-80. 
Lee, J. F., Cadierno, T., Glass, W. R., \& VanPatten, B. (1997). The effects of lexical and grammatical cues on processing past temporal reference in second language input. Applied Language Learning, 8, 1-23.

Lew-Williams, C., \& Fernald, A. (2007). How first and second language learners use predictive cues in online sentence interpretation in Spanish and English. In H. Caunt-Nulton, S. Kulatilake, \& I. Woo (Eds.), Proceedings of the 31st Annual Boston University conference on language development (pp. 382-393). Somerville, MA: Cascadilla Press.

Lin, J.-W. (2006). Time in a language without tense: The case of Chinese. Journal of Semantics, $23,1-53$.

Long, M. H. (1991). Focus on form: A design feature in language teaching methodology. In K. de Bot, R. Ginsberg, \& C. Kramsch (Eds.), Foreign language research in cross-cultural perspective (pp. 39-52). Amsterdam: Benjamins.

Mackintosh, N. J. (1975). A theory of attention: Variations in the associability of stimuli with reinforcement. Psychological Review, 82, 276-298.

MacWhinney, B. (1987). The competition model. In B. MacWhinney (Ed.), Mechanisms of language acquisition (pp. 249-308). Mahwah, NJ: Erlbaum.

MacWhinney, B. (1997). Second language acquisition and the competition model. In A. M. B. De Groot \& J. F. Kroll (Eds.), Tutorials in bilingualism: Psycholinguistic perspectives (pp. 113-142). Mahwah, NJ: Erlbaum.

MacWhinney, B. (2001). The competition model: The input, the context, and the brain. In P. Robinson (Ed.), Cognition and second language instruction (pp. 69-90). New York: Cambridge University Press.

MacWhinney, B., \& Bates, E. (1989). The crosslinguistic study of sentence processing. New York: Cambridge University Press.

MacWhinney, B., Bates, E., \& Kliegl, R. (1984). Cue validity and sentence interpretation in English, German, and Italian. Journal of Verbal Learning and Verbal Behavior, 23, 127-150.

Mangubhai, F. (1991). The processing behaviors of adult second language learners and their relationship to second language proficiency. Applied Linguistics, 12, 268-297.

Matessa, M., \& Anderson, J. R. (2000). Modeling focused learning in role assignment. Language and Cognitive Processes, 15, 263-292.

McDonald, J. L. (1986). The development of sentence comprehension strategies in English and Dutch. Journal of Experimental Child Psychology, 41, 317-335.

Meisel, J. (1987). Reference to past events and actions in the development of natural second language acquisition. In C. Pfaff (Ed.), First and second language acquisition (pp. 206-224). Rowley, MA: Newbury House.

Musumeci, D. (1989). The ability of second language learners to assign tense at the sentence level: A cross-linguistic study. Unpublished doctoral dissertation, University of Illinois at Urbana-Champaign.

Nelson, K. (1991). The matter of time: Interdependencies between language and thought in development. In S. A. Gelman \& J. P. Byrnes (Eds.), Perspectives on language and thought: Interrelations in development (pp. 278-318). New York: Cambridge University Press.

Nelson, K. (1996). Language in cognitive development. New York: Cambridge University Press.

Noyau, C., Klein, W., \& Dietrich, R. (1995). Acquisition of temporality in a second language. Amsterdam: Benjamins.

Odlin, T. (1989). Language transfer. New York: Cambridge University Press.

Pawlak, A., Oehlrich, J., \& Weist, R. (2006). Reference time in child English and Polish. First Language, 26, 281-297.

Perdue, C. (Ed.). (1993). Adult language acquisition: Crosslinguistic perspectives. New York: Cambridge University Press.

Pica, T. (1983). Adult acquisition of English as a second language under different conditions of exposure. Language Learning, 33, 465-497.

Rescorla, R. A., \& Wagner, A. R. (1972). A theory of Pavlovian conditioning: Variations in the effectiveness of reinforcement and nonreinforcement. In A. H. Black \& W. F. Prokasy (Eds.), Classical conditioning II: Current theory and research (pp. 64-99). New York: Appleton-Century-Crofts.

Robinson, P., \& Ellis, N. C. (Eds.). (2008). A handbook of cognitive linguistics and second language acquisition. London: Routledge. 
Rossomondo, A. E. (2007). The role of lexical temporal indicators and tense interaction format in the incidental acquisition of the Spanish future tense. Studies in Second Language Acquisition, 29, 39-66.

Sagarra, N. (2001, October). Attention allocation to morphological cues during L2 sentence processing: Evidence from eye-movement. Paper presented at the IV Conference on the Acquisition of Spanish and Portuguese as First and Second Languages, UrbanaChampaign, IL.

Sagarra, N. (2007). Working memory and L2 processing of redundant grammatical forms. In Z. Han (Ed.), Second language processing and instruction: Broadening the scope of inquiry (pp. 142-159). Clevedon, UK: Multilingual Matters.

Sagarra, N., \& Ellis, N. C. (2010). Learned attention and blocking in the acquisition of L2 tense. Unpublished manuscript.

Sato, M., \& Felser, C. (2008). Sensitivity to morphosyntactic violations in English as a second language. Unpublished manuscript, Department of Language and Linguistics, University of Essex.

Schmidt, R. (1984). The strengths and limitations of acquisition: A case study of an untutored language learner. Language, Learning, and Communication, 3, 1-16.

Schmidt, R. (1993). Awareness and second language acquisition. Annual Review of Applied Linguistics, 13, 206-226.

Schmidt, R. (2001). Attention. In P. Robinson (Ed.), Cognition and second language instruction (pp. 3-32). New York: Cambridge University Press.

Schneider, W., Eschman, A., \& Zuccolotto, A. (2002). E-Prime user's guide. Pittsburgh, PA: Psychology Software Tools, Inc.

Schumann, J. H. (1978). The pidginization process: A model for second language acquisition. Rowley, MA: Newbury House.

Schumann, J. H. (1987). The expression of temporality in basilang speech. Studies in Second Language Acquisition, 9, 21-41.

Shanks, D. R. (1995). The psychology of associative learning. New York: Cambridge University Press.

Simon, H. A. (1957). Models of man: Social and rational. New York: Wiley.

Swain, M. (2005). The output hypothesis: Theory and research. In E. Hinkel (Ed.), Handbook of research in second language teaching and learning (pp. 471-484). Mahwah, NJ: Erlbaum.

Terrell, T. (1991). The role of grammar instruction in a communicative approach. Modern Language Journal, 75, 52-63.

Valian, V. (2006). Young children's understanding of present and past tense. Language Learning and Development, 2, 251-276.

VanPatten, B. (1996). Input processing and grammar instruction in second language acquisition. Westport, CT: Ablex.

VanPatten, B. (2006). Input processing. In B. VanPatten \& J. Williams (Eds.), Theories in second language acquisition: An introduction (pp. 115-136). Mahwah, NJ: Erlbaum.

Weist, R., Atanassova, M., Wysocka, H., \& Pawlak, A. (1999). Spatial and temporal systems in child language and thought: A cross-linguistic study. First Language, 19, 267-312.

White, L. (2003). Second language acquisition and Universal Grammar. New York: Cambridge University Press.

Wills, A. J. (2005). New directions in human associative learning. Mahwah, NJ: Erlbaum.

Xiao, R., \& McEnery, T. (2004). Aspect in Mandarin Chinese. Amsterdam: Benjamins.

Zipf, G. K. (1949). Human behaviour and the principle of least effort: An introduction to human ecology. Cambridge, MA: Addison-Wesley.

Zobl, H., \& Liceras, J. M. (1994). Functional categories and acquisition orders. Language Learning, 44, 159-180. 